\title{
Effect of ursodeoxycholic acid treatment on ileal absorption of bile acids in man as determined by the SeHCAT test
}

\author{
S Eusufzai, S Ericsson, T Cederlund, K Einarsson, B Angelin
}

\begin{abstract}
The effects of ursodeoxycholic acid on ileal absorption of bile acids and on serum bile acid and lipoprotein concentrations were studied. Eight healthy subjects were investigated. The $\gamma$ emitting bile acid analogue, SeHCAT, was given orally and its fractional catabolic rate and seven day retention were assessed by repeated external counting over the upper abdomen during the next seven days. Ursodeoxycholic acid was then given orally at a dose of $15 \mathrm{mg} / \mathrm{kg}$ day for three weeks and the study was repeated during treatment. The fractional catabolic rate increased by $64 \%$ (mean (SD), $0.333(0.159) v$ $0.203(0.061) /$ day; $p<0.05)$ and seven day retention decreased by $44 \%$ (15 (10) $v 27(10) \%$, $\mathbf{p}<\mathbf{0 . 0 0 1}$, indicating bile acid malabsorption. Total serum cholesterol fell from $5 \cdot 79(1 \cdot 22)$ to $5.50(1.18) \mathrm{mmol} / \mathrm{l}(\mathrm{p}=0.05)$, while serum ursodeoxycholic acid increased 22 fold $(7.87$ (2.67) $v 0.34(0.24) \mu \mathrm{mol} / \mathrm{l}, \mathrm{p}<0.001)$. Five of the subjects continued taking $30 \mathrm{mg} / \mathrm{kg} /$ day of ursodeoxycholic acid for one week and showed an increase in fractional catabolic rate of $81 \%$ $(0.300(0.091) v 0.166(0.037) /$ day; $p<0.05)$ and a fall in seven day retention of $50 \%(16(12) v 32$ $(8) \%, p<0.01)$. There were significant reductions in total cholesterol $(5.36(1.71) v 6.08$ $(1.47) \mathrm{mmol} / \mathrm{l} ; \mathrm{p}<0.05)$ and low density lipoprotein cholesterol $(3.70(1.33) v 4.58(1.16)$ $\mathrm{mmol} / \mathrm{l} ; \mathrm{p}<0 \cdot 05)$. The results support the concept that ursodeoxycholic acid treatment interferes with the absorption of endogenous bile acids, and emphasise the beneficial effects of this treatment on lipoprotein concentrations in man.
\end{abstract}

The primary bile acids, cholic acid and chenodeoxycholic acid, are formed from cholesterol in the liver and stored in the gall bladder in the fasting state. 'In response to a meal, bile acids are excreted into the intestine where they contribute to the efficient absorption of dietary fat and cholesterol. The secondary bile acids, deoxycholic acid and lithocholic acid, are the result of dehydroxylation of cholic acid and chenodeoxycholic acid by intestinal bacteria. The reabsorption of bile acids is very efficient, particularly because of active uptake in the distal ileum. The synthesis of bile acids is regulated by a homeostatic mechanism in which bile acids returning to the liver from the intestine inhibit their own synthesis. ${ }^{2}$ The demand for hepatic cholesterol increases where bile acid synthesis is stimulated, and this is met by an increased cholesterol synthesis as well as by an increased expression of the low density lipoprotein receptors. ${ }^{3}$ Thus, disturbances in bile acid kinetics may influence low density lipoprotein catabolism in several clinical situations.

Ursodeoxycholic acid, which is the $7 \beta$ epimer of chenodeoxycholic acid, is a minor constituent of the normal bile pool acid in man. ${ }^{4}$ Its clinical use has become important in the treatment of cholesterol gall stones, ${ }^{4}$ primary biliary cirrhosis, ${ }^{5}$ and sclerosing cholangitis. ${ }^{6}$ Oral administration of ursodeoxycholic acid makes the bile unsaturated with cholesterol because of reduced cholesterol secretion. ${ }^{478}$ In contrast to treatment with chenodeoxycholic acid, the synthesis of primary bile acids is not suppressed during ursodeoxycholic acid treatment. ${ }^{79}$ When ursodeoxycholic acid becomes the major bile acid secreted, the absorption of dietary and biliary cholesterol is reduced through the decreased micellar solubilisation power of this bile acid. ${ }^{101}$ Finally, there may be competition between ursodeoxycholic acid and the other bile acids for the intestinal bile acid transport system. ${ }^{9}$

Bile acid absorption can now be determined by using ${ }^{75}$ Selenium homocholic acid taurine ( ${ }^{75} \mathrm{SeHCAT}$ ), a synthetic analogue of the natural conjugated bile acid taurocholic acid with the $\gamma$ emitter ${ }^{75} \mathrm{Se}$ in the side chain. ${ }^{1213}$ It has been shown in previous studies that SeHCAT behaves like the natural bile acid with regard to enterohepatic cycling, hepatic handling, active absorption from the terminal ileum, faecal excretion, and overall turnover in the enterohepatic circulation. ${ }^{12-16}$ The only difference is that SeHCAT undergoes negligible deconjugation by colonic bacteria

This investigation was undertaken to study the effect of treatment with ursodeoxycholic acid on endogenous bile acid absorption using the SeHCAT technique. A detailed study was performed simultaneously on the effects on plasma lipoprotein values and serum bile acid composition.

\section{Methods}

SUBJECTS

This study comprised eight healthy normolipidaemic volunteers with relative body weight $<120 \%$ (Table I). All of them took $15 \mathrm{mg} / \mathrm{kg} /$ day of ursodeoxycholic acid and five of them later continued with $30 \mathrm{mg} / \mathrm{kg} / \mathrm{day}$. After a basal clinical and laboratory evaluation excluding heart, kidney, thyroid, liver disease, and diabetes, they were followed closely as outpatients and allowed to continue their normal diet. Informed consent was obtained from each sub- 
TABLE I Basal data on the subjects

\begin{tabular}{llll}
\hline & \multicolumn{3}{l}{ Bodyweight } \\
\cline { 3 - 4 } Subject no/sex & Age (yrs) & $\mathrm{kg}$ & Relative (\%) \\
\hline l/M & 44 & 90 & 120 \\
$2 / \mathrm{M}$ & 36 & 64 & 88 \\
$3 / \mathrm{M}$ & 34 & 81 & 103 \\
$4 / \mathrm{M}$ & 31 & 56 & 81 \\
$5 / \mathrm{M}$ & 48 & 75 & 88 \\
$6 / \mathrm{M}$ & 31 & 74 & 82 \\
$7 / \mathrm{M}$ & 40 & 94 & 91 \\
$8 / \mathrm{F}$ & 29 & 58 &
\end{tabular}

ject, and the ethical aspects of the study were approved by the Ethical Committee of the Karolinska Institute, Stockholm.

\section{EXPERIMENTAL PROCEDURE}

Basal data obtained before the start of ursodeoxycholic acid treatment included fasting blood samples for serum lipid, lipoprotein, and bile acids concentrations.

SeHCAT $(10 \mu \mathrm{Ci}$, Amersham International) was given orally with a drink of water following the technique described by Thaysen ${ }^{13}$ and Delhez et $a l .{ }^{14}$ The initial count rate (100\% value) was measured three hours after the intake of isotope (day 0), with the subject lying in supine and prone position under an uncollimated gamma camera (Porta Camera, General Electric. Nuclear Medical ApS, Denmark). The distance from the bed to the gamma camera crystal was maintained at $75 \mathrm{~cm}$ and the crystal ( $\mathrm{Na} \mathrm{I})$ was centred over the middle of the xiphoidoumbilical line. The count rate in a $25 \%$ window centred around the 265 and $280 \mathrm{KeV}$ photon peaks of ${ }^{75} \mathrm{Se}$ was measured. The measurements, which took 10 minutes (five minutes each position), were repeated on days 2,4 , and 7 after the administration of the capsule. The background activity was subtracted and correction was made for the decay of the isotope. The geometric means of the counts measured in the anterior and posterior positions were plotted in a logarithmic-linear graph. An exponential function was fitted to the data points using the method of least squares. The $\mathrm{T}_{\frac{1}{2}}$ - that is the time when the abdominal retention of the SeHCAT was reduced to $50 \%$ of initial, was calculated from the curve, as well as the fractional catabolic rate defined as $\ln 2 / \mathrm{T}_{\frac{1}{2}}$.

After completing the SeHCAT test the sub- jects were given ursodeoxycholic acid (Ursofalk, Dr Falk GmbH \& Co, Germany, purity >99\%) in a dose of $15 \mathrm{mg} / \mathrm{kg} /$ day for three weeks. Fasting blood samples (obtained 12-14 hours after intake) were then collected again, and the SeHCAT test was repeated. The treatment was continued during the studies. After completing the second SeHCAT test, five of the subjects increased the dose of ursodeoxycholic acid to 30 $\mathrm{mg} / \mathrm{kg} /$ day in order to load further the bile acid transport system. Fasting blood samples were collected after one week, and the SeHCAT test was repeated during continued 'high dose' treatment.

\section{BIOCHEMICAL ANALYSIS}

\section{Serum lipoproteins}

Cholesterol and triglyceride concentrations were determined with automated enzymatic techniques (Boehringer Mannheim Test Combination Cholesterol and Triglycerides, respectively). Serum lipoprotein analysis was performed by a combination of ultracentrifugation and precipitation. ${ }^{17}$

\section{Serum bile acids}

Serum together with added internal standards $\left({ }^{2} \mathrm{H}_{5}\right.$-cholic acid, ${ }^{2} \mathrm{H}_{4}$-chenodeoxycholic acid, ${ }^{2} \mathrm{H}_{5}$ deoxycholic acid, and ${ }^{2} \mathrm{H}_{3}$-ursodeoxycholic acid) was subjected to hydrolysis, acidification, and methylation. The methylated extracts were silylated and analysed by gas chromatography mass spectrometry with an NERMAG R10-10H Quadropol instrument equipped with a multiple ion detector unit. Details of the method have been described elsewhere. ${ }^{18}$

\section{STATISTICAL ANALYSIS}

The results are expressed as mean (SD) values. The statistical significance of differences was evaluated by Student's paired $t$ test.

\section{Results}

Giving ursodeoxycholic acid at a dose of 15 $\mathrm{mg} / \mathrm{kg} /$ day resulted in increased excretion of SeHCAT in all subjects (Table II). The mean fractional catabolic rate increased by $64 \%$, from $0.203(0.061)$ to $0.333(0 \cdot 159) /$ day (mean (SD);

TABLE II Effect of treatment with ursodeoxycholic acid (UDCA) on fractional catabolic rate (FCR) (/day) and $T \frac{1}{2}$ (days) of SeHCAT

\begin{tabular}{|c|c|c|c|c|c|c|c|c|c|}
\hline \multirow[b]{2}{*}{ Subject no } & \multicolumn{3}{|l|}{ Basal } & \multicolumn{3}{|c|}{ UDCA treatment, $15 \mathrm{mg} / \mathrm{kg} / \mathrm{day}$} & \multicolumn{3}{|c|}{ UDCA treatment, $30 \mathrm{mg} / \mathrm{kg} / \mathrm{day}$} \\
\hline & $F C R$ & $T \frac{1}{2}$ & $\begin{array}{l}\text { Retention at } \\
\text { day } 7(\%)\end{array}$ & $F C R$ & $T \frac{1}{2}$ & $\begin{array}{l}\text { Retention at } \\
\text { day } 7(\%)\end{array}$ & $F C R$ & $T \frac{1}{2}$ & $\begin{array}{l}\text { Retention at } \\
\text { day } 7(\%)\end{array}$ \\
\hline $\begin{array}{l}1 \\
2 \\
3 \\
4 \\
5 \\
6 \\
7 \\
8\end{array}$ & $\begin{array}{l}0.162 \\
0.144 \\
0.183 \\
0.218 \\
0.122 \\
0.303 \\
0.242 \\
0.250\end{array}$ & $\begin{array}{l}4 \cdot 27 \\
4 \cdot 80 \\
3 \cdot 79 \\
3 \cdot 18 \\
5 \cdot 68 \\
2 \cdot 29 \\
2 \cdot 86 \\
2 \cdot 77\end{array}$ & $\begin{array}{l}32 \\
37 \\
28 \\
22 \\
43 \\
13 \\
19 \\
18\end{array}$ & $\begin{array}{l}0.196 \\
0.274 \\
0.328 \\
0.279 \\
0.192 \\
0.693 \\
0.385 \\
0.318\end{array}$ & $\begin{array}{l}3.53 \\
2.53 \\
2 \cdot 11 \\
2.48 \\
3.61 \\
1.00 \\
1.80 \\
2 \cdot 18\end{array}$ & $\begin{array}{c}25 \\
25 \\
10 \\
14 \\
27 \\
<1 \\
8 \\
10\end{array}$ & $\begin{array}{l}0.283 \\
0.354 \\
0.343 \\
0.371 \\
0.149\end{array}$ & $\begin{array}{l}2.45 \\
1.96 \\
2.02 \\
1.87 \\
4.65\end{array}$ & $\begin{array}{r}16 \\
9 \\
9 \\
8 \\
36\end{array}$ \\
\hline $\begin{array}{l}\text { Mean (SD) } \\
(1-8) \\
(1-5)\end{array}$ & $\begin{array}{l}0.203(0.061) \\
0.166(0.037)\end{array}$ & $\begin{array}{l}3.70(1.15) \\
4.34(0.96)\end{array}$ & $\begin{array}{l}27(10) \\
32(8)\end{array}$ & $\begin{array}{l}0.333(0.1599)^{\star} \\
0.254(0.059)\end{array}$ & $\begin{array}{l}2.41(0.86) \dagger \\
2.85(0.68)\end{array}$ & $\begin{array}{l}15(10) \ddagger \\
20(8)\end{array}$ & $0.300(0.091)^{\star}$ & $2 \cdot 59(1 \cdot 17) \dagger$ & $16(12) \dagger$ \\
\hline
\end{tabular}

${ }^{\star} \mathrm{p}<0.05 ; \mathrm{tp}<0.01 ; \neq \mathrm{p}<0.001$ compared with basal value. 
TABLE III Effects of ursodeoxycholic acid (UDCA) on serum bile acids (values mean (SD))

\begin{tabular}{lcc}
\hline Bile acids & $\begin{array}{l}\text { Basal } \\
(\mu \mathrm{mol} / \mathrm{l})\end{array}$ & $\begin{array}{l}\text { UDCA } \\
(\mu \mathrm{mol} / \mathrm{l})\end{array}$ \\
\hline $\begin{array}{l}\text { (a) 8 Patients, UDCA } 15 \mathrm{mg} / \mathrm{kg} / \text { day } \\
\text { Cholic acid }\end{array}$ & $0.75(0.59)$ & $0.73(0.32)$ \\
Chenodeoxycholic acid & $1.71(0.84)$ & $1.71(0.50)$ \\
Deoxycholic acid & $0.81(0.46)$ & $0.66(0.36)$ \\
Ursodeoxycholic acid & $0.34(0.24)$ & $7.87(2.67) \dagger$ \\
(b) 5 Patients, UDCA 30 & $\mathrm{mg} / \mathrm{kg} /$ day & \\
Cholic acid & $0.95(0.69)$ & $0.68(0.53)$ \\
Chenodeoxycholic acid & $1.90(1.03)$ & $2.18(2.38)$ \\
Deoxycholic acid & $0.93(0.51)$ & $0.85(0.90)$ \\
Ursodeoxycholic acid & $0.27(0.24)$ & $11.37(4.13)^{\star}$ \\
\hline
\end{tabular}

${ }^{\star} \mathrm{p}<0.005,+\mathrm{p}<0.001 v$ basal values.

TABLE IV Effect of ursodeoxycholic acid treatment (UDCA) on plasma lipid concentrations (values mean (SD))

\begin{tabular}{|c|c|c|}
\hline Lipids & Basal ( mmol/l) & $\begin{array}{l}\text { UDCA } \\
(\mathrm{mmol} / \mathrm{l})\end{array}$ \\
\hline \multicolumn{3}{|c|}{ (a) 8 Patients, UDCA $15 \mathrm{mg} / \mathrm{kg} /$ day } \\
\hline Total cholesterol & $5 \cdot 79(1 \cdot 22)$ & $5 \cdot 50(1 \cdot 18)^{\star}$ \\
\hline Triglycerides & $1.26(0.87)$ & $1.26(0.60)$ \\
\hline VLDL cholesterol & $0.50(0.37)$ & $0.52(0.33)$ \\
\hline LDL cholesterol & $4.24(1.02)$ & $3.84(0.94)$ \\
\hline HDL cholesterol & $1.06(0.27)$ & $1 \cdot 15(0.39)$ \\
\hline VLDL triglycerides & $0.74(0.68)$ & $0.69(0.57)$ \\
\hline \multicolumn{3}{|c|}{ (b) 5 Patients, UDCA $30 \mathrm{mg} / \mathrm{kg} /$ day } \\
\hline Total cholesterol & $6.08(1.47)$ & $5 \cdot 36(1 \cdot 71) \dagger$ \\
\hline Triglycerides & $1.40(1.04)$ & $1.06(0.48)$ \\
\hline VLDL cholesterol & $0.52(0.43)$ & $0.52(0.22)$ \\
\hline LDL cholesterol & $4.58(1 \cdot 16)$ & $3.70(1.33)+$ \\
\hline HLD cholesterol & $1.00(0.25)$ & $1.12(0.44)$ \\
\hline VLDL triglycerides & $0.80(0.78)$ & $0.58(0.36)$ \\
\hline
\end{tabular}

$\star$ Significantly different from basal value, $p=0.05 ; \mathrm{tp}<0.05$. $V L D L=$ very low density lipoprotein; $L D L=$ low density lipoprotein; $\mathrm{HDL}=$ high density lipoprotein

$\mathrm{p}<0.05)$, and the $\mathrm{T}_{\frac{1}{2}}$ decreased from $3.70(1 \cdot 15)$ to $2.41(0.86)$ days $(\mathrm{p}<0.05)$. In the five subjects who continued taking the 'high' dose of ursodeoxycholic acid, there was a still more pronounced increase in the fractional catabolic rate compared with basal values $(0.300(0.091) v$ $0.166(0.037) /$ day, $\mathrm{p}<0.05)$. Accordingly, the $\mathrm{T}_{\frac{1}{2}}$ decreased from $4.34(0.96)$ to $2.59(1.17)$ days $(p<0.005)$. The seven day retention of SeHCAT (\%) was reduced from 27 (10) to 15 $(10) \%(\mathrm{p}<0.001)$ during the $15 \mathrm{mg} / \mathrm{kg} /$ day dose, while with the 'high' dose it fell from $32(8)$ to 16 (12)\% $(\mathrm{p}<0.01)$.

Serum bile acid analysis during ursodeoxycholic acid administration showed a significant increase in the ursodeoxycholic acid concentration $(7.87(2.67) v 0.34(0.24) \mu \mathrm{mol} / \mathrm{l} ; \mathrm{p}<0.001)$ and an even greater one during 'high' dose treatment $(11.34(4 \cdot 13) v 0.27(0.24) \mu \mathrm{mol} / \mathrm{l}$; $\mathrm{p}<0.005)$, while there was no significant change in the concentrations of the other bile acids (Table III).

During treatment with $15 \mathrm{mg} / \mathrm{kg} / \mathrm{day}$, the only significant change in plasma lipids was a decrease in the total cholesterol concentration from 5.79 $(1 \cdot 22)$ to $5.50(1 \cdot 18) \mathrm{mmol} / \mathrm{l}(\mathrm{p}=0.05)$, reflecting a (non-significant) reduction of the concentration of low density lipoprotein cholesterol from $4 \cdot 24$ $(1.02)$ to $3.84(0.94) \mathrm{mmol} / \mathrm{l}$ (Table IV). During 'high' dose ursodeoxycholic acid administration there was a further significant decrease from the basal values in the total cholesterol concentration (from 6.08 (1.47) to $5.36(1.71) \mathrm{mmol} / \mathrm{l} ; \mathrm{p}<0.05$ ) and low density lipoprotein cholesterol (from $4.58(1 \cdot 16)$ to $3.7(1 \cdot 33) \mathrm{mmol} / \mathrm{l} ; \mathrm{p}<0.05)$. There were no significant changes in total or very low density lipoprotein triglycerides or very low density or high density lipoprotein cholesterol during treatment at either dosage.

\section{Discussion}

Several distinct effects of ursodeoxycholic acid on bile acid and cholesterol metabolism in normolipidaemic humans are evident from the present study. Firstly, we could show directly a dose related interaction with the absorption of SeHCAT, indicating competitive inhibition of the intestinal uptake of this radiolabelled bile acid analogue. Since SeHCAT has very similar physiological properties to taurocholic acid, a disturbance of its reabsorption should reflect interaction with the active transport system in the terminal ileum. A tendency for an increased fractional catabolic rate of radiolabelled cholic acid during ursodeoxycholic acid treatment has also been observed during kinetic studies in humans, ${ }^{9}$ but the present approach should give a more sensitive detection since SeHCAT is stable and does not undergo deconjugation by colonic bacteria. ${ }^{16}$

Although the molecular properties of the intestinal bile acid carrier are not yet known in detail, physiological studies have indicated that the transport system has a preference for trihydroxy bile acids and that it is working relatively close to saturation under physiological conditions. ${ }^{119}$ An increased load of exogenous ursodeoxycholic acid should thus preferentially interfere with the enterohepatic circulation of cholic acid. In accordance with this contention, the excretion of cholic acid was increased somewhat more than that of chenodeoxycholic acid during short term administration of ursodeoxycholic acid to patients with ileostomy. ${ }^{20}$ Such an exclusion of cholic acid (and chenodeoxycholic acid) from the enterohepatic circulation would result in reduced amounts of primary bile acids being returned to the liver via the portal venous circulation. Since ursodeoxycholic acid does not seem to suppress bile acid synthesis ${ }^{721}$ or the activity of its rate limiting enzyme, cholesterol $7 \alpha$-hydroxylase, ${ }^{22}$ such treatment would result in an increase in bile acid production in order to maintain the pool sizes of these bile acids.

A second new finding in this study emerges from the determination of individual serum bile acid concentrations (Table III). In agreement with previous studies, ${ }^{18}$ the administration of 15 $\mathrm{mg} / \mathrm{kg} /$ day of ursodeoxycholic acid leads to a large increase in the serum concentration of this bile acid, whereas there were no significant changes in the concentrations of cholic acid, chenodeoxycholic acid, or deoxycholic acid. This indicates that despite the increased loss of endogenous bile acid during ursodeoxycholic acid therapy, the pool sizes of these bile acids were maintained. This concept could now be extended to treatment with large amounts of ursodeoxycholic acid ( $30 \mathrm{mg} / \mathrm{kg} /$ day), where still no changes in serum bile acid concentrations could be observed, despite a more than $\mathbf{4 0}$ fold increase in ursodeoxycholic acid serum concentrations. It should be noted that all these measurements refer to the fasting state, and that a reduced return of bile acids may be present postprandially, as has recently been shown 
during cholestyramine treatment. ${ }^{23}$ The data in this study are thus in agreement with the concept of a stimulated bile acid production during ursodeoxycholic acid treatment, and such an effect could at least partially explain why the secretion rate of cholesterol into bile is reduced..$^{7-9}$

A third finding was a dose related decrease in plasma total and low density lipoprotein cholesterol concentrations (Table IV). A cholesterol lowering effect of ursodeoxycholic acid has been noted in some previous studies, ${ }^{24} 25$ but this is not a universal finding. ${ }^{+}$The effect is in clear contrast to observations during chenodeoxycholic acid therapy, where low density lipoprotein cholesterol and the low:high density lipoprotein ratios are frequently increased..$^{26-28}$ It is reasonable to assume that the difference between the two bile acids relates to their differing effects on hepatic cholesterol metabolism. Thus, chenodeoxycholic acid is known to suppress drastically bile acid biosynthesis, ${ }^{72}$ mediated via down regulation of the cholesterol $7 \alpha$-hydroxylase. ${ }^{22}$ This in turn creates a decreased hepatic demand for cholesterol, resulting in reduced activity of HMG CoA reductase ${ }^{30}$ as well as a tendency for reduced low density lipoprotein receptor expression. ${ }^{31}$ The latter effect is probably the explanation for the approximately $10 \%$ increase in low density lipoprotein cholesterol which has been reported. ${ }^{26-28}$ On the other hand, as discussed above, ursodeoxycholic acid slightly increases the activity of cholesterol $7 \alpha$-hydroxylase ${ }^{22}$ and bile acid production rate. ${ }^{721}$ This would lead to an increased hepatic demand for cholesterol, reflected in an unchanged or slightly stimulated activity of HMG CoA reductase. ${ }^{24}{ }^{32}$ It is reasonable to assume that the low density lipoprotein receptor expression is stimulated, and such a phenomenon could well explain the decrease in low density lipoprotein cholesterol concentrations, particularly since there is no evidence of an effect on the very low density lipoprotein production rate. ${ }^{9}$ Another mechanism that is probably operative during ursodeoxycholic acid therapy is a reduced absorption of dietary and biliary cholesterol because of the reduced capacity to form micelles. ${ }^{10111733}$

In conclusion, treatment with ursodeoxycholic acid results in a dose dependent reduction of intestinal bile acid reabsorption. The unchanged serum concentrations of cholic acid, chenodeoxycholic acid, and deoxycholic acid indicate a stimulated bile acid production rate with unchanged pools. In addition, ursodeoxycholic acid treatment is associated with lowering of total and low density lipoprotein cholesterol, hypothetically as the result of stimulation of low density lipoprotein receptor expression secondary to an increased hepatic cholesterol demand. Compared with chenodeoxycholic acid, this effect on lipoprotein concentrations should be an advantage during long term treatment in gall stone disease.

The skilful technical assistance of Ms Sabine Süllow, Ms Lilian Larsson and Ms Gunvor Alvelius and the manuscript preparation of Ms Lena Ericsson is gratefully acknowledged. This study was supported by grants from the Axel Ax:son Johnson Foundation and the Swedish Medical Research Council (03X-7137 and
$03 \mathrm{X}-4793)$. Dr Eusufzai is the recipient of a scholarship from the Swedish Institute.
This work was presented at the Second International Meeting on Pathochemistry, Pathophysiology, and Pathomechanics of the Biliary System and New Strategies for the Treatment of Hepatobiliary Diseases, Bologna, Italy, March 1990.

1 Carey MC, Cahalane MJ. Enterohepatic circulation. In: Arias IM, Jakoby WB, Popper H, Schachter D, and Shafritz DA eds. The liver: biology and pathobiology. New York: Raven eds. The liver: biology
Press 1988: 573-616.

2 Björkhem I. Mechanism of bile acid biosynthesis in mammalian liver. In: Danielsson $\mathrm{H}$, Sjövall J, eds. Comprehensive biochemistry. Amsterdam: Elsevier 1985: 231-78.

3 Angelin B. Regulation of hepatic lipoprotein receptor expression. In Calandra S, Carulli N, and Salvioli G, eds. Liver and lipid metabolism. Amsterdam: Elsevier 1984; 187-201

4 Bachrach WH, Hofmann AF. Ursodeoxycholic acid in the treatment of cholesterol cholelithiasis. Dig Dis Sci 1982; 27: 737-61, 833-56.

5 Poupon R, Chretien Y, Poupon RE, Ballet F, Calmus Y, Darnis F. Is ursodeoxycholic acid an effective treatment for primary biliary cirrhosis. Lancet 1987; i: 834-6.

6 Stiehl A, Raedsch R, Kommerell B. The effect of ursodeoxycholic acid in primary sclerosing cholangitis. A comparison to primary biliary cirrhosis. Gastroenterology 1988 94: A595.

7 Nilsell K, Angelin B, Leijd B, Einarsson K. Comparative effects of ursodeoxycholic acid and chenodeoxycholic acid on bile acid kinetics and biliary lipid secretion in humans. Evidence for different modes of action on bile acid synthesis. Gastroenterology 1983; 85: 1248-56.

8 von Bergmann K, Epple-Gutsfeld M, Leiss O. Differences in the effects of chenodeoxycholic acid and ursodeoxycholic acid on biliary lipid secretion and bile acid synthesis in patients with gallstones. Gastroenterology 1984; 87: 136-43.

9 Angelin B, Nilsell K, Einarsson K. Ursodeoxycholic acid Angelin B, Nilsell K, Einarsson K. Ursodeoxycholic acid
treatment in humans: effects on plasma and biliary lipid treatment in humans: effects on plasma and biliary lipid
metabolism with special reference to very low density lipoprotein triglyceride and bile acid kinetics. Eur $\mathcal{F}$ Clin Invest 1986; 16: 169-77.

10 Ponz de Leon M, Carulli N, Loria P, Iori R, Zironi F Cholesterol absorption during bile acid feeding. Effect of ursodeoxycholic acid administration. Gastroenterology 1980 78: 214-9.

11 Leiss O, von Bergmann K, Streicher U, Strotkoetter H. Effect of three different dihydroxy bile acids on intestinal cholesterol absorption in normal volunteers. Gastroenterology 1984; 87: 14-9.

12 Merrick MV, Eastwood MA, Anderson JR, Ross HM. Enterohepatic circulation in man of a gamma-emitting bile acid conjugate, 23-selena-25 homocholic acid taurine (SeHCAT) f Nucl Med 1982; 23: 126-30.

13 Thaysen EH. Assessment of ileal function by abdominal counting of the retention of a gamma emitting bile acid analogue. Gut 1982; 23: 862-5

14 Galatola G, Jazrawi RP, Bridges C, Joseph AEA, Northfield TC. Hepatic handling of the synthetic-labelled bile acid SeHCAT. Gastroenterology 1988; 94: 771-8.

15 Delhez $H$, van den Berg JWO, van Blankenstein $M$, Meerwaldt JH. New method for the determination of bile acid turnover using ${ }^{75} \mathrm{Se}$-homocholic acid taurine. Eur f Nucl Med 1982; 7: 269-71

16 Jazrawi RP, Ferraris R, Bridges C, Northfield TC. Kinetics for synthetic bile acid ${ }^{75}$ Selenohomocholic acid-taurine in humans: comparison with $\left[{ }^{1+} \mathrm{C}\right]$ taurocholate. Gastroenterology 1988; 95: 164-9.

17 Carlson K. Lipoprotein fractionation. $\mathcal{F}$ Clin Pathol 1973; 26: 32-7.

18 Ewerth S, Angelin B, Einarsson K, Nilsell K, Björkhem I Serum concentration of ursodeoxycholic acid in portal venous and systemic venous blood of fasting humans as determined by isotope dilution mass spectrometry. Gastroenterology 1985; 88: 126-33.

$19 \mathrm{Krag}$ E, Phillips SF. Active and passive bile acid absorption in man. Perfusion studies in the ileum and jejunum. $\mathcal{F}$ Clin man. Perfusion studies in

20 Stiehl A, Raedsch R, Rudolph G. Acute effects of ursodeoxycholic and chenodeoxycholic acid on the small intestina absorption of bile acids. Gastroenterology 1990; 98: 424-8.

21 Hardison WG, Grundy SM. Effect of ursodeoxycholate and its taurine conjugate on bile acid synthesis and cholesterol absorption. Gastroenterology 1984; 87: 130-5.

22 Reihnér E, Björkhem I, Angelin B, Ewerth S, Einarsson $\mathrm{K}$ Bile acid synthesis in humans: regulation of hepatic microsomal cholesterol $7 \alpha$-hydroxylase activity. Gastroenterology 1989; 97: 1498-1505.

23 Angelin B, Björkhem I, Einarsson K, Ewerth S. Cholestyramine treatment reduces postprandial but not fasting serum bile acid levels in humans. Gastroenterology 1982; 83 . 1097-101.

24 Angelin B, Ewerth S, Einarsson K. Ursodeoxycholic acid treatment in cholesterol gallstone disease: effects on hepatic 3-hydroxy-3-methylglutaryl coenzyme A reductase activity, 3-hydroxy-3-methylglutaryl coenzyme A reductase activity,
biliary lipid composition, and plasma lipid levels. $F$ Lipid Res biliary lipid comp

25 Einarsson K, Björkhem I, Eklöf R, Ewerth S, Nilsell K, and Blomstrand R. Effect of ursodeoxycholic acid treatment on intestinal absorption of triglyc
Gastroenterol 1984; 19: 283-8.

26 Angelin B, Einarsson K, Leijd B. Clofibrate treatment and bile cholesterol saturation. Short-term and long-term effects and influence of combination with chenodeoxycholic acid. Eur $\mathcal{J}$ Clin Invest 1981; 11: 185-9.

27 Albers JJ, Grundy SM, Cleary PA, Small DM, Lachin JM Schoenfield LJ, and the National Cooperative Gallstone 
Study Group. National Cooperative Gallstone Study. The effect of chenodeoxycholic acid on lipoproteins and apolipoproteins. Gastroenterology 1982; 82: 638-46.

28 Leijd B, Angelin B. Effects of chenodeoxycholic acid and cholic acid feeding on plasma lipoproteins and cholesterol absorption in hyperlipoproteinemia: a crossover study. In: Paumgartner G, Stiehl A, Gerok W, eds. Bile acids and cholesterol in health and disease. London: MTP Press, 1983: 191-201.

29 LaRusso NF, Hoffman NE, Hofmann AF, Northfield TC Thistle JL. Effect of primary bile acid ingestion on bile acid metabolism and biliary lipid secretion in gallstone patients. Gastroenterology 1975; 69: 1301-14.

30 Angelin B, Einarsson K. Regulation of HMG CoA reductase in human liver. In: Preiss B, ed. Regulation of $H M G C o A$ reductase. New York: Academic Press, 1985: 281-320.

31 Angelin B, Reihnér E, Rudling M, Ewerth S, Björkhem I, Einarsson $\mathrm{K}$. In vitro studies of lipid metabolism in human liver. Am Heart $\mathcal{F}$ 1987; 113: 482-7.

32 Carulli N, Ponz de Leon M, Zironi F, Pinetti A, Smerieri A Iori R, Loria P. Hepatic cholesterol and bile acid metabolism in subjects with gallstones: Com in subiectict 7 Lipid Res 1980; $21: 35-43$.

33 Lanzini A, Jazrawi RP, Northfield TC. Effect of ursodeoxycholic acid on biliary lipid coupling and on cholesterol absorption during fasting and eating in subjects with cholesterol gallstones. Gastroenterology 1988; 95: 408-16. 